\title{
Improving the Usability and Safety of Digital Health Systems: The Role of Predictive Human-Computer Interaction Modeling
}

Chris Paton ${ }^{1,2}$, BMedSci, BMBS, MBA; Andre W Kushniruk ${ }^{3}$, BSc, BA, MSc, PhD; Elizabeth M Borycki ${ }^{3}, \mathrm{RN}$, HBScN, MN, PhD; Mike English ${ }^{1}$, MBBChir, MD, FMedSci; Jim Warren ${ }^{4}$, BS, PhD

\footnotetext{
${ }^{1}$ Nuffield Department of Medicine, University of Oxford, Oxford, United Kingdom

${ }^{2}$ Department of Information Science, University of Otago, Dunedin, New Zealand

${ }^{3}$ School of Health Information Science, University of Victoria, Victoria, BC, Canada

${ }^{4}$ School of Computer Science, University of Auckland, Auckland, New Zealand
}

\section{Corresponding Author:}

Chris Paton, BMedSci, BMBS, MBA

Nuffield Department of Medicine

University of Oxford

Peter Medawar Building

South Parks Road

Oxford, OX1 3SY

United Kingdom

Phone: 447552698058

Email: chris.paton@ndm.ox.ac.uk

\section{Abstract}

In this paper, we describe techniques for predictive modeling of human-computer interaction (HCI) and discuss how they could be used in the development and evaluation of user interfaces for digital health systems such as electronic health record systems. Predictive HCI modeling has the potential to improve the generalizability of usability evaluations of digital health interventions beyond specific contexts, especially when integrated with models of distributed cognition and higher-level sociotechnical frameworks. Evidence generated from building and testing HCI models of the user interface (UI) components for different types of digital health interventions could be valuable for informing evidence-based UI design guidelines to support the development of safer and more effective UIs for digital health interventions.

(J Med Internet Res 2021;23(5):e25281) doi: 10.2196/25281

\section{KEYWORDS}

digital health; human-centered design; usability; human-computer interaction; predictive modeling

\section{Introduction}

User interfaces for digital health systems such as electronic health records (EHRs) or clinical decision support systems should be designed so that clinicians can accomplish tasks efficiently without making errors that could compromise patient safety. Designers of digital health systems should be able to use the best research evidence currently available, drawn from systematic reviews and meta-analyses, to inform their designs. However, the evidence base for designing user interfaces (UIs) of digital health systems has been difficult to establish, as evaluations of UIs are often subjective and difficult to generalize to new clinical contexts [1]. Recent systematic reviews of usability issues with different types of digital health systems (such as computerized physician order entry [2] and electronic medical records [3]) highlight some common issues identified across different studies but also describe the difficulties in generalizing guidance from context-specific evaluations. This evidence is of use to designers but does not offer specific design patterns or quantitatively demonstrate the trade-offs between efficiency and effectiveness that may be involved in different approaches to making designs more usable. Partly due to the weakness of the scientific evidence base, usability guidelines have therefore generally recommended adopting a human-centered design (HCD) approach and the use of expert heuristics to guide the design of interfaces rather than quantitatively validated design patterns.

In this paper, we examine how the use of human-computer interaction (HCI) predictive models can contribute to building a more robust and generalizable evidence base for UI designs for digital health interventions. This evidence base could then 
be used to advance UI design guidelines and could be incorporated in the human-centered design process to accelerate innovation and improve clinical safety.

HCI modeling was used to develop the first computer mouse $[4,5]$ and the modern window-based graphical UIs in wide use today [6]. As digital health systems become widely (albeit often reluctantly) adopted in health care, HCI modeling could have an important role in ensuring that the systems we use to care for patients are as safe and effective as other medical innovations such as drugs and diagnostics.

To discuss this approach, we provide a summary of the historical origins of predictive HCI modeling, show examples of how it can be used in modern digital health system design, and show how HCI modeling can be integrated into the human-centered design process.

\section{The Digital Health Design Evidence Gap}

The current best practice for designing UIs for digital health systems is to use a human-centered design (HCD) approach such as "design thinking" [7], in which designers and developers move through an iterative and flexible process of understanding, exploring, and materializing the end product (Figure 1). This process is often guided by design heuristics ("rules of thumb") that include such guidance as keeping the UI simple and aesthetically pleasing and ensuring that help and documentation are readily available (see Textbox 1 for the 10 Nielsen heuristics) $[8,9,10]$. Iterative design thinking methods attempt to ensure that systems are aligned with users' behaviors and needs and allow for improvements to be made throughout the course of the design process.

Figure 1. Human-centered design helps designers move from computer code to real-world use. Adapted from Gibbons [7].

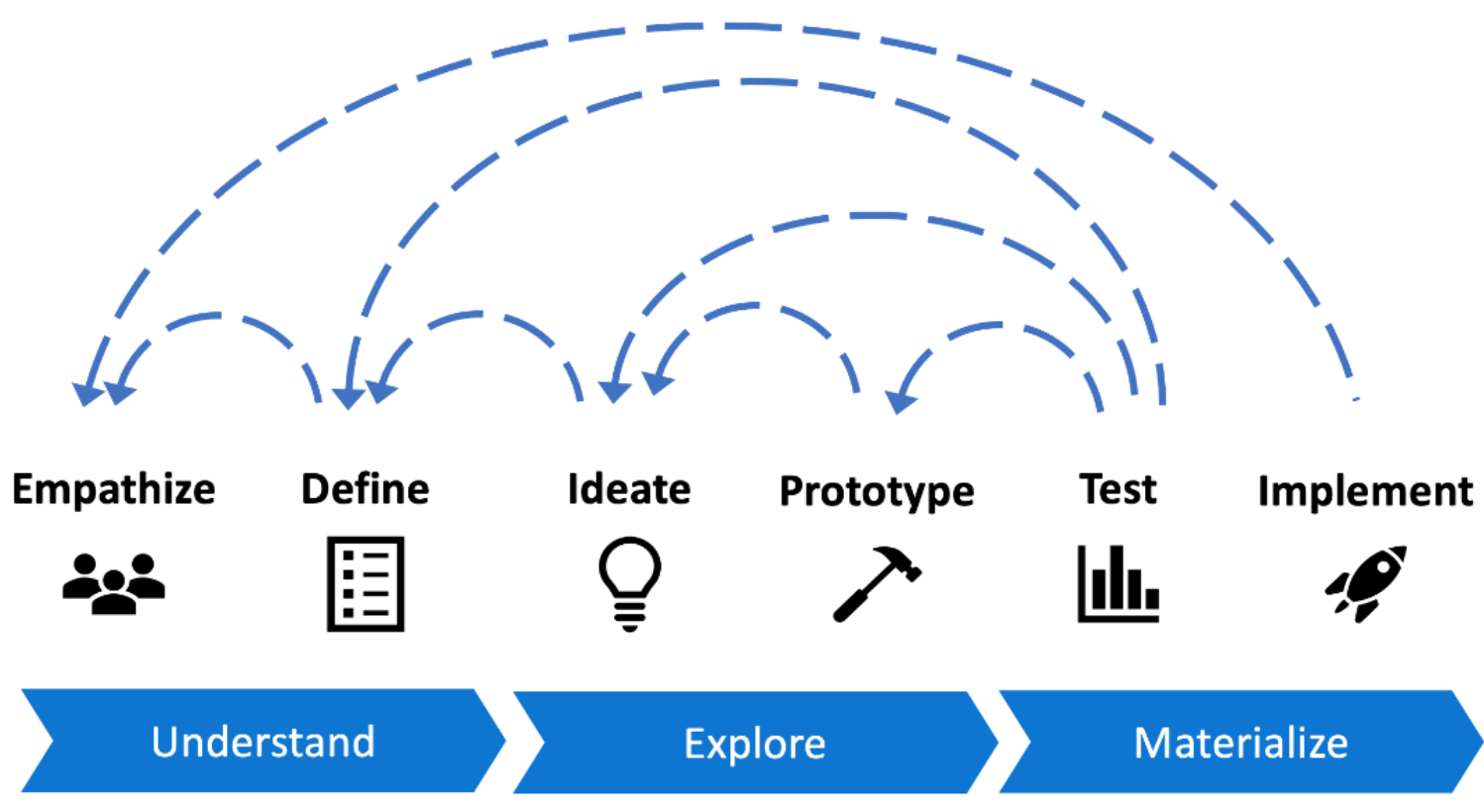

Textbox 1. The 10 Nielsen usability heuristics.

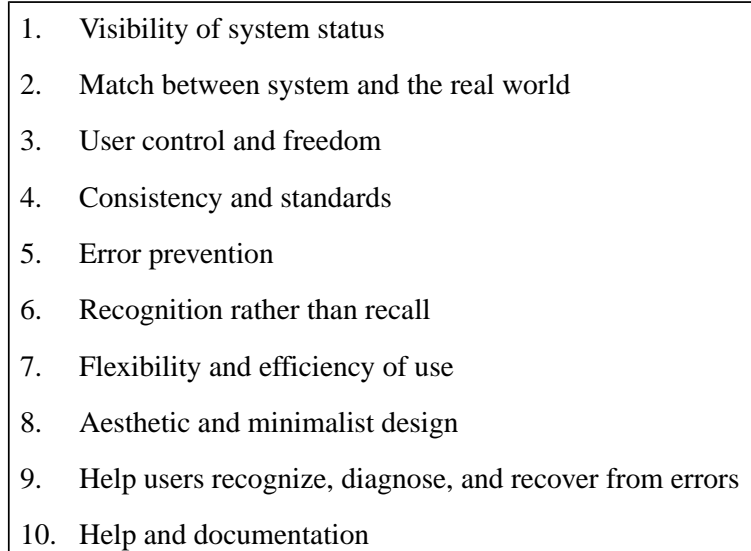


HCD has been developed to ensure that UIs work well for specific contexts but does not provide the kind of evidence normally expected for medical interventions. HCD should be part of the design process; however, additional methods are needed with a more scientific basis to be confident that digital health UI designs are suitable for use in high-risk settings such as hospitals.

\section{Predictive Models of $\mathrm{HCl}$}

Predictive HCI models have the potential to explain how users interact with digital health interventions at the level of individual human cognition. For more than 50 years, empirically derived predictive HCI models have been used for ensuring the safety and usability of information systems (physical and digital) for industrial and commercial applications ranging from avionics to power plant control systems. These models informed the designs of the first desktop computers, with innovations such as the computer mouse and windows-based graphical UIs. The "classic" HCI model was called the "model human processor," in which the different components of human cognitive systems were modeled and combined with models of the interactions (inputs and outputs) between the human and the computer system (see Figure 2).

Figure 2. The model human processor: a model of how long it takes to process information (from perception to action) and how we can use the limited "chunks" of information in working memory. Building on the idea of a model human processor is the concept of "distributed cognition," with multiple humans and devices working together. Adapted from Card et al [11].

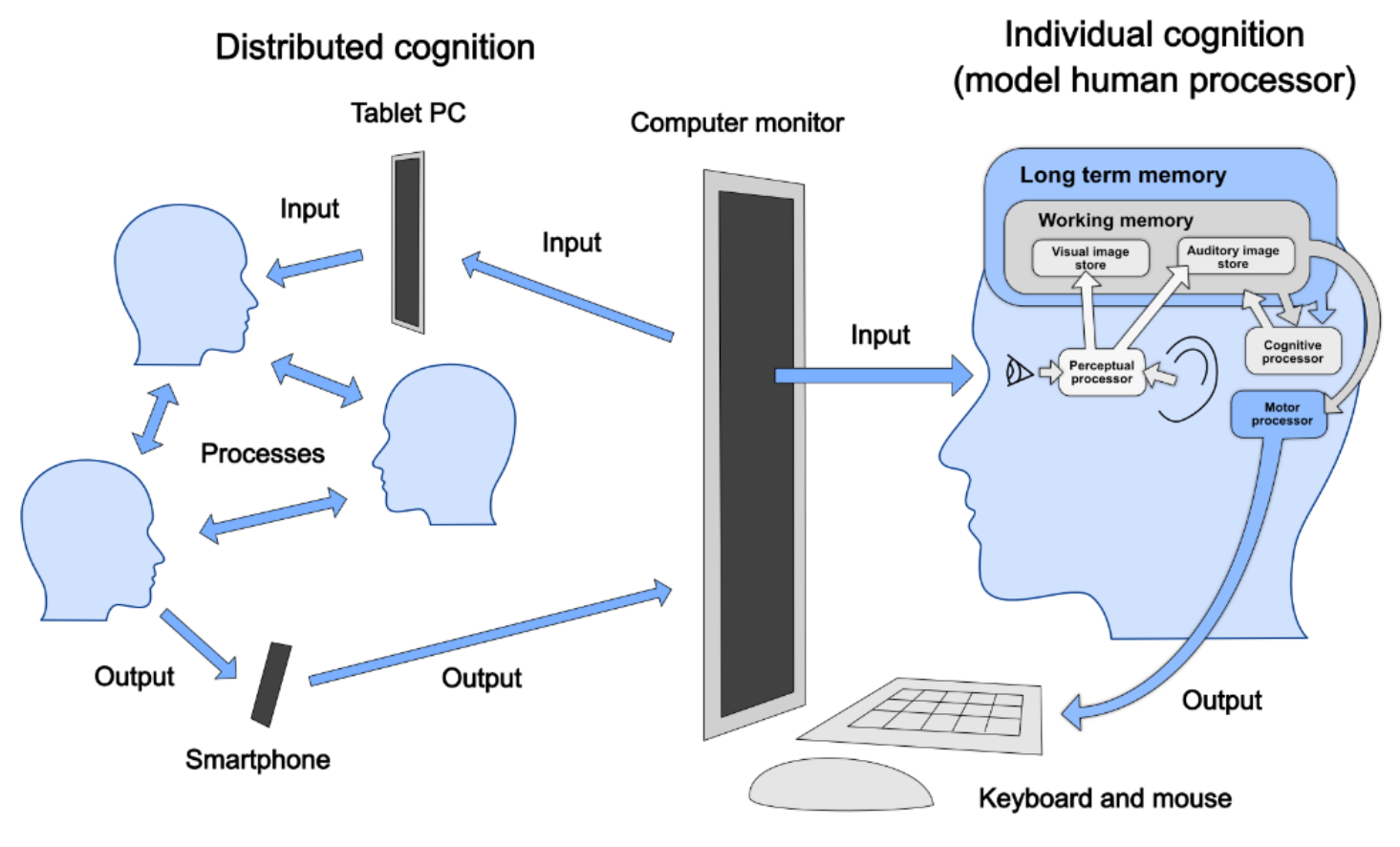

There are now several types of HCI predictive models that can be used depending on the context or type of tasks analyzed. For example, the Fitts law is used for mouse pointing [12], the Hick-Hyman law is used for reviewing a sorted list [13,14], and goals operators methods and selection rules (GOMS) [15] is a high-level model that is used to describe the cognitive processes and methods involved in using a computer to achieve specific goals. The keystroke-level model (KLM) is a more specific type of GOMS model that is used for compositions of tasks that fit how an experienced user interacts with the interface [11]. KLM has also recently been updated for touch interfaces [16] Although individuals will vary in their performance speed, these models give a good indication of the relative effort required to accomplish a task. For example, Warren et al and others [17-19] have used such models for simulation-based evaluation of split-menu designs (placing commonly accessed options at the top of a list) for clinical information systems. These models are primarily aimed at reducing the time needed to complete tasks by eliminating unnecessary clicks and ensuring that UI elements are easy to navigate. In the health care domain, simplifying designs and increasing efficiency is also likely to reduce errors that can cause patient harm, such as choosing incorrect items from unnecessarily long menus or clicking through lengthy screens too quickly $[20,21]$.

\section{Limitations of $\mathrm{HCl}$ Modeling}

Although the abovementioned models proved useful and effective in the design of early graphical UIs and input devices, the ways in which teams of people began to use computer systems in the 1990s prompted a move in HCI research communities away from the micro-level interactions to meso-level systems of "distributed cognition" [22] (Figure 2) and "situated action" [23]. These systems included the described cognitive models by attempting to place them within a social context, with human-human interaction playing a role in addition to machine-machine interaction (Figure 2 shows how distributed cognition can be integrated with micro-level HCI modeling). In the health care domain, Borycki and Kushniruk [20,24-26] led the development of an integrative cognitive-sociotechnical 
model for characterizing user interactions with health care systems at multiple levels.

The field of cognitive science has also moved on since HCI modeling was first proposed. The human cognitive system processes information in a highly complex manner, with dynamic feedback loops that are not included in the ways that HCI models are traditionally described. Therefore, HCI modeling has been more recently viewed as a useful tool for assisting in the development of systems rather than the scientific pursuit originally envisaged by Card, Moran, and Newell in their classic text "The Psychology of Human-Computer Interaction" [15]. However, recent work, such as on the representation of "M" (for "mentally prepare") in the KLM model, shows that more nuanced and complex models can be created where more fidelity to human cognition is required.

\section{Example of the "Combined" Layered Approach to Collecting Evidence About $\mathrm{HCl}$}

In their study of electronic whiteboards across Denmark, Rasmussen and Kushniruk [27] incorporated the KLM model; however, this work was initially driven by a naturalistic study to locate workflow issues associated with deployment of a new electronic whiteboard across several hospitals across Denmark. The naturalistic study identified areas where optimization might be needed, as evidenced by observation of seemingly inefficient user interactions with the whiteboard (identified from review of the screen recordings of user interactions), and the KLM experimental approach was then used to test hypotheses on applying different changes to create efficiencies.

The research team video recorded 2863 entries from video analysis of live user interactions with the whiteboard and identified potential inefficient sequences from observing and timing the video (eg, the task "add new patient" took an average of 12.3 seconds). They then conducted GOMS-KLM analysis producing the following predictive model ( $\mathrm{H}=$ move hands; $\mathrm{M}=$ mentally prepare; $\mathrm{K}=$ tap key or button; $\mathrm{P}=$ point):

$\mathrm{H}+\mathrm{M}+\mathrm{P}+\mathrm{K}+\mathrm{M}+\mathrm{P}+\mathrm{K}+\mathrm{H}+\mathrm{M}+(\mathrm{K} * 10)+\mathrm{H}+\mathrm{M}+\mathrm{P}+\mathrm{K}+\mathrm{P}+\mathrm{K}+\mathrm{H}+\mathrm{M}+$ $(\mathrm{K} * 30)+\mathrm{H}+\mathrm{M}+\mathrm{P}+\mathrm{K}+\mathrm{M}+\mathrm{P}+\mathrm{K}+\mathrm{M}+\mathrm{P}+\mathrm{K}+\mathrm{M}+\mathrm{P}+\mathrm{K}+\mathrm{M}+\mathrm{P}+\mathrm{K}+$ $\mathrm{M}+\mathrm{P}+\mathrm{K}+\mathrm{M}+\mathrm{P}+\mathrm{K}+\mathrm{M}+\mathrm{P}+\mathrm{K}+\mathrm{M}+\mathrm{P}+\mathrm{K}+\mathrm{M}+\mathrm{P}+\mathrm{K}+\mathrm{M}+\mathrm{P}+\mathrm{K}+\mathrm{M}+\mathrm{P}+\mathrm{K}$ $=54.6$ seconds

They then modified the "add new patients" task so that instead of opening new dialog boxes, information could be directly entered into text boxes or from menus, modeled thus:

$\mathrm{H}+\mathrm{M}+\mathrm{P}+\mathrm{K}+\mathrm{M}+\mathrm{P}+\mathrm{K}+\mathrm{H}+\mathrm{M}+\mathrm{K}+\left(\mathrm{K}^{*} 10\right)+\mathrm{H}+\mathrm{M}+\mathrm{P}+\mathrm{K}+\mathrm{H}+\mathrm{M}+$ $(\mathrm{K} * 30)+\mathrm{H}+\mathrm{M}+\mathrm{P}+\mathrm{K}+\mathrm{M}+\mathrm{P}+\mathrm{K}+\mathrm{M}+\mathrm{P}+\mathrm{K}+\mathrm{M}+\mathrm{P}+\mathrm{K}=31.25$ seconds

The results of the project led to a reduction in time to task completion of $44.6 \%$ and illustrated the benefits of considering HCI at multiple levels (ie, including the use of naturalistic observation and video coding of those data for the use of KLM to predict more optimal user designs for improving inefficient user interaction sequences).

\section{HCl Model Patterns for Different Types of Digital Health Systems}

Digital health applications may have common usability and resultant patient safety issues that can be modeled using predictive HCI approaches as shown above. However, specific types of digital health interventions may also have type-specific UI patterns that, if modeled as a common function of a particular type of system, may make it easier to develop more general models. Using the World Health Organization Digital Health Intervention (DHI) classification system [28], it could be envisaged that each type of system, such as a telemedicine system (DHI 2.4) or health care provider training system (DHI 2.8 ), would have a common HCI predictive model that takes into account the cognitive processes involved in using that type of system. For example, a training system would include cognitive models of how the system enables the user to learn how to manage a clinical problem, retain the knowledge over time (perhaps by repeatedly "topping up" their knowledge), and recall the information when needed.

\section{Implications for Developing Guidelines and Standards for Digital Health Systems}

Safety issues with large-scale EHR systems have now started to be reported in the literature. Recent work by Ratwani et al $[29,30]$ has highlighted a wide range of usability issues in currently used digital health systems. The analysis by Pacheco et al [31] of the Certified Health IT Product List database of usability attestation, for example, revealed that $3.7 \%$ of the products surveyed had a certified capability nonconformity issue that was coded as being associated with possible patient harm. Despite these ongoing issues with clinical usability, current guidance on digital health system development has largely taken a heuristic approach [32], building on and adapting the Nielsen heuristics for health care contexts [3]. Several large-scale projects have been undertaken to develop UI guidelines; however, without establishing an evidence-based approach to guideline development, it has been difficult to maintain or build on these guidelines as technology develops. For example, in the United Kingdom, the National Health Service commissioned Microsoft to develop a "Common User Interface" for EHR systems designed as part of the National Programme for Information Technology; however, this guidance was recently withdrawn without replacement [33]. In the United States, the Department of Health and Human Services created "Research-Based Web Design and Usability Guidelines" [34].

Although these approaches can aid the design of systems that adhere to industrial usability standards, they represent a broad-brush approach that lacks the kind of scientific rigor required by other health care interventions, such as new pharmaceuticals.

Greater consideration and use of predictive models integrated into an HCD approach may be needed to ensure that evidence-based UI design guidelines can be developed over time. The results of modeling-based studies could ensure that systematic reviews and meta-analyses of usability studies 
generate evidence that is generalizable beyond the specific contexts of the studies.

\section{Integrating Predictive Modeling With HCD}

Using predictive models to inform the HCD process could accelerate the design of digital health systems. By having a validated evidence base of UI designs to draw on, designers could eliminate a large number of potential designs that might meet basic usability heuristics or that could be appealing to early testers but that could be shown through predictive modeling to have poor usability. Figure 3 shows how HCI modeling could fit into the process of designing the UI for a digital health application. The design process moves from implementing the computer algorithms needed for the software to function (developed using deductive logic with a high level of epistemic certainty) to modeling how users would interact with the UI of the system using HCI cognitive models. Once designs that show poor results with modeling are weeded out, the project will then enter a human-centered design phase in which the system is trialed with real users (for example, nurses and physicians who will use a digital health system on the wards) and repeatedly iterated until the software is sufficiently acceptable to pilot. At this stage, human-in-the-loop simulations can be conducted as the system is piloted. Finally, more formal quantitative and qualitative evaluations in clinical contexts can provide higher-level empirical evidence (albeit with lower epistemic certainty than with in-silico HCI modeling). At each stage, in keeping with the design thinking approach, the development team can move back to modeling and HCD to improve the design if needed. In addition to showing whether a particular application works, real-world evaluations based on HCI models will show which models work in the real world, building the evidence base for future design guidelines.

Figure 3. Predictive human-computer interaction modeling could augment the human-centered design process and help us understand how an application achieves real-world effectiveness.

\section{Iterate models based on observations}

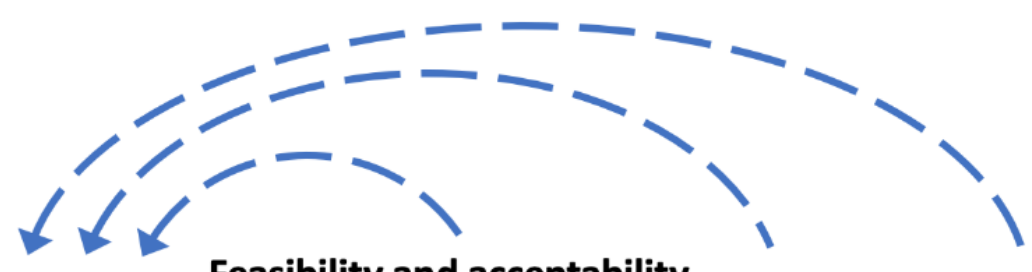

Hypothesis Model

Feasibility and acceptability

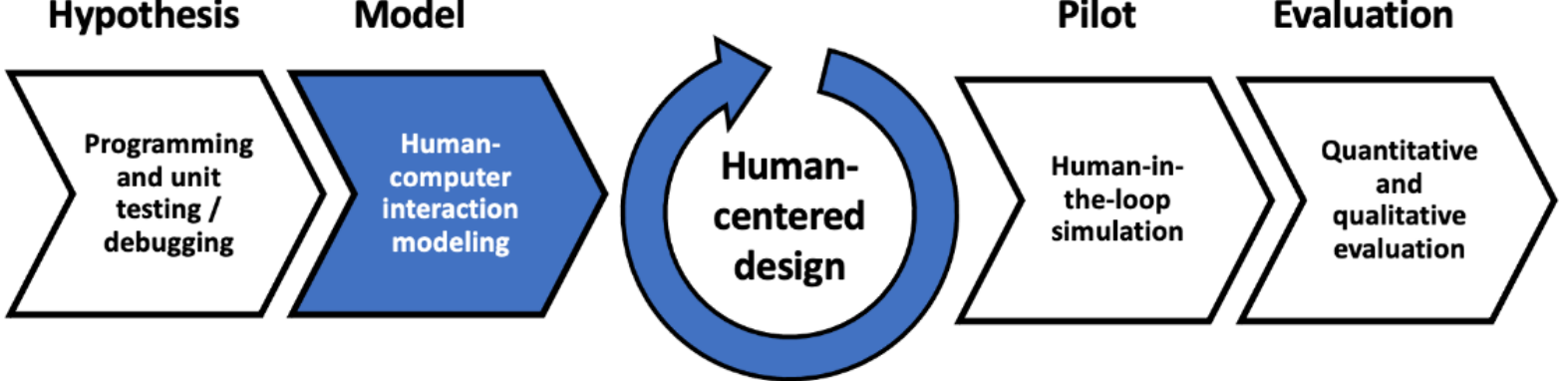

\section{Computer algorithms \\ Add model of human}

Add real humans
Add context
Deductive Logic

(High epistemic certainty)
Empirical testing

(Low epistemic certainty)

\section{Conclusion}

UIs for digital health applications are currently designed using techniques developed for commercial software applications based on human-centered design processes and heuristics. Predictive HCI modeling of applications may help improve the design process and allow for more scientific progress toward safer and more effective digital health systems. We have described in this paper how predictive HCI modeling has developed from individual cognitive modeling to distributed cognitive models and provided examples of how these models can be integrated into sociotechnical modeling approaches. Although predictive HCI modeling has fallen out of favor in recent years, as the demand for more evidence of the safety and effectiveness of digital health systems increases, it is worth re-evaluating whether HCI modeling can contribute to the science of evidence-based digital health system design. Future 
research on the integration of predictive modeling with usability and software engineering approaches (such as usability testing and human-in-the-loop simulations) is both needed and warranted.

\section{Acknowledgments}

This viewpoint paper resulted from a panel discussion session by the authors on the topic of HCI modeling at the International Medical Informatics Association MedInfo Conference held in Lyon, France, in 2019. We are grateful to the attendees of the session for their helpful comments and questions during the panel discussion.

This research was funded by the National Institute for Health Research (NIHR; NIHR130812: Learning to Harness Innovation in Global Health for Quality Care (HIGH-Q)) using UK aid from the UK Government to support global health research. The views expressed in this publication are those of the authors and not necessarily those of the NIHR or the UK Department of Health and Social Care.

\section{Conflicts of Interest}

None declared.

\section{References}

1. Rigby M, Ammenwerth E. The Need for Evidence in Health Informatics. Stud Health Technol Inform 2016;222:3-13. [Medline: 27198087]

2. Khajouei R, Jaspers MWM. The impact of CPOE medication systems' design aspects on usability, workflow and medication orders: a systematic review. Methods Inf Med 2010;49(1):3-19. [doi: 10.3414/ME0630] [Medline: 19582333]

3. Zahabi M, Kaber DB, Swangnetr M. Usability and Safety in Electronic Medical Records Interface Design: A Review of Recent Literature and Guideline Formulation. Hum Factors 2015 Aug;57(5):805-834. [doi: 10.1177/0018720815576827] [Medline: 25850118]

4. Card SK, English WK, Burr BJ. Evaluation of Mouse, Rate-Controlled Isometric Joystick, Step Keys, and Text Keys for Text Selection on a CRT. Ergonomics 2007 Apr 25;21(8):601-613. [doi: 10.1080/00140137808931762]

5. English W, Engelbart D, Berman M. Display-Selection Techniques for Text Manipulation. IEEE Trans. Human Factors Electron 1967 Mar;HFE-8(1):5-15. [doi: 10.1109/thfe.1967.232994]

6. Scott MI. Human-Computer Interaction: An Empirical Research Perspective. Burlington, Massachusetts, United States: Morgan Kaufmann; 2013.

7. Gibbons S. Design Thinking 101. Nielsen Norman Group. URL: https://www.nngroup.com/articles/design-thinking/ [accessed 2020-06-23]

8. Nielsen N. 10 usability heuristics for user interface design. Norman Nielsen Group. 2020. URL: https://www.nngroup.com/ articles/ten-usability-heuristics/ [accessed 2021-05-12]

9. Nielsen J. Enhancing the explanatory power of usability heuristics. : ACM; 1994 Presented at: CHI94: SIGCHI Conference on Human Factors in Computing Systems; 1994; Boston Massachusetts USA. [doi: 10.1145/191666.191729]

10. Nielsen J. Heuristics for user interface design. Nielsen Norman Group. URL: https://www.nngroup.com/articles/ ten-usability-heuristics/ [accessed 2020-06-23]

11. Card SK, Moran TP, Newell A. The keystroke-level model for user performance time with interactive systems. Commun. ACM 1980 Jul;23(7):396-410. [doi: 10.1145/358886.358895]

12. Fitts PM. The information capacity of the human motor system in controlling the amplitude of movement. Journal of Experimental Psychology 1954;47(6):381-391. [doi: 10.1037/h0055392]

13. Hick WE. On the Rate of Gain of Information. Quarterly Journal of Experimental Psychology 2018 Jan 01;4(1):11-26. [doi: $10.1080 / 17470215208416600]$

14. Hyman R. Stimulus information as a determinant of reaction time. Journal of Experimental Psychology 1953;45(3):188-196. [doi: 10.1037/h0056940]

15. Card S, Newell A, Moran T. The Psychology of Human-Computer Interaction. Boca Raton, Florida, United States: CRC Press; Feb 01, 1986.

16. Rice A, Lartigue J. Touch-level model (TLM). 2014 Presented at: ACM SE '14: Proceedings of the 2014 ACM Southeast Regional Conference; 2014; Kennesaw Georgia p. 1-6. [doi: 10.1145/2638404.2638532]

17. Canfield K. Priming intelligent split menus with text corpora for computerized patient record data-entry. International Journal of Bio-Medical Computing 1995 May;39(2):263-273. [doi: 10.1016/0020-7101(95)01108-Q]

18. Warren JR, Bolton P. Intelligent split menus for data entry: a simulation study in general practice medicine. Proc AMIA Symp 1999:450-454 [FREE Full text] [Medline: 10566399]

19. Sears A, Shneiderman B. Split menus. ACM Trans. Comput.-Hum. Interact 1994 Mar;1(1):27-51. [doi: 10.1145/174630.174632] 
20. Borycki E, Kushniruk A, Nohr C, Takeda H, Kuwata S, Carvalho C, et al. Usability Methods for Ensuring Health Information Technology Safety: Evidence-Based Approaches. Contribution of the IMIA Working Group Health Informatics for Patient Safety. Yearb Med Inform 2013;8:20-27. [Medline: 23974544]

21. Marcilly R, Peute L, Beuscart-Zephir M. From Usability Engineering to Evidence-based Usability in Health IT. Stud Health Technol Inform 2016;222:126-138. [doi: 10.3233/978-1-61499-635-4-126]

22. Hollan J, Hutchins E, Kirsh D. Distributed cognition. ACM Trans. Comput.-Hum. Interact 2000 Jun;7(2):174-196. [doi: $10.1145 / 353485.353487]$

23. Bardram J. Plans as Situated Action: An Activity Theory Approach to Workflow Systems. Dordrecht: Springer; 1997 Presented at: Fifth European Conference on Computer Supported Cooperative Work; 1997; Netherlands. [doi: 10.1007/978-94-015-7372-6_2]

24. Kushniruk A, Nohr C, Borycki E. Human Factors for More Usable and Safer Health Information Technology: Where Are We Now and Where do We Go from Here? Yearb Med Inform 2016(1):120-125. [doi: 10.15265/iy-2016-024]

25. Borycki E, Kushniruk A, Keay E, Nicoll J, Anderson J, Anderson M. Toward an Integrated Simulation Approach for Predicting and Preventing Technology-Induced Errors in Healthcare: Implications for Healthcare Decision-Makers. hcq 2009 Aug 15;12(sp):90-96. [doi: 10.12927/hcq.2009.20974]

26. Kushniruk A, Patel V. Cognitive and usability engineering methods for the evaluation of clinical information systems. J Biomed Inform 2004 Feb;37(1):56-76 [FREE Full text] [doi: 10.1016/j.jbi.2004.01.003] [Medline: 15016386]

27. Rasmussen R, Kushniruk A. The long and twisting path: an efficiency evaluation of an electronic whiteboard system. Stud Health Technol Inform 2013;183:174-178. [Medline: 23388277]

28. World HO. Classification of Digital Health Interventions.: World Health Organization; 2018. URL: https://apps.who.int/ iris/handle/10665/260480 [accessed 2020-02-19]

29. Howe JL, Adams KT, Hettinger AZ, Ratwani RM. Electronic Health Record Usability Issues and Potential Contribution to Patient Harm. JAMA 2018 Mar 27;319(12):1276. [doi: 10.1001/jama.2018.1171]

30. Ratwani RM, Savage E, Will A, Fong A, Karavite D, Muthu N, et al. Identifying Electronic Health Record Usability And Safety Challenges In Pediatric Settings. Health Affairs 2018 Nov;37(11):1752-1759. [doi: 10.1377/hlthaff.2018.0699]

31. Pacheco TB, Hettinger AZ, Ratwani RM. Identifying Potential Patient Safety Issues From the Federal Electronic Health Record Surveillance Program. JAMA 2019 Dec 17;322(23):2339. [doi: 10.1001/jama.2019.17242]

32. Middleton B, Bloomrosen M, Dente MA, Hashmat B, Koppel R, Overhage JM, et al. Enhancing patient safety and quality of care by improving the usability of electronic health record systems: recommendations from AMIA. J Am Med Inform Assoc 2013 Jun;20(e1):e2-e8 [FREE Full text] [doi: 10.1136/amiajnl-2012-001458] [Medline: 23355463]

33. Edgar M. Why we are deprecating and then withdrawing the NHS Common User Interface - NHS Digital. NHS Digital. 2019 Jul 04. URL: https://digital.nhs.uk/blog/transformation-blog/2019/why-we-are-withdrawing-the-nhscommon-user-interface [accessed 2019-12-18]

34. Shneiderman B, Leavitt M, Others. Research-based web design \& usability guidelines. Washington DC: Department of Health and Human Services; 2006.

\author{
Abbreviations \\ DHI: digital health intervention \\ EHR: electronic health record \\ GOMS: goals operators methods and selection rules \\ HCD: human-centered design \\ HCI: human-computer interaction \\ KLM: keystroke-level model \\ UI: user interface
}

Edited by R Kukafka; submitted 26.10.20; peer-reviewed by A Hilt, R Marcilly, E Andrikopoulou, D Lin, J Ye; comments to author
23.12.20; revised version received 17.02.21; accepted 16.03.21; published 27.05.21
Please cite as:
Paton C, Kushniruk AW, Borycki EM, English M, Warren J
Improving the Usability and Safety of Digital Health Systems: The Role of Predictive Human-Computer Interaction Modeling
J Med Internet Res 2021;23(5):e25281
URL: https://www.jmir.org/2021/5/e25281
doi: $\underline{10.2196 / 25281}$
PMID: 
(C) Chris Paton, Andre W Kushniruk, Elizabeth M Borycki, Mike English, Jim Warren. Originally published in the Journal of Medical Internet Research (https://www.jmir.org), 27.05.2021. This is an open-access article distributed under the terms of the Creative Commons Attribution License (https://creativecommons.org/licenses/by/4.0/), which permits unrestricted use, distribution, and reproduction in any medium, provided the original work, first published in the Journal of Medical Internet Research, is properly cited. The complete bibliographic information, a link to the original publication on https://www.jmir.org/, as well as this copyright and license information must be included. 